\title{
In support of selective rehearsal: Double-item presentation in item-method directed forgetting
}

\author{
Pelin Tan ${ }^{1} \cdot$ Tyler M. Ensor ${ }^{2} \cdot$ William E. Hockley ${ }^{3} \cdot$ Geoffrey W. Harrison ${ }^{4} \cdot$ Daryl E. Wilson $^{4}$
}

Published online: 26 March 2020

(C) The Psychonomic Society, Inc. 2020

\begin{abstract}
Despite the substantial evidence highlighting the role of selective rehearsal in item-method directed forgetting, recent work has suggested that forgetting may occur as a function of an active inhibitory mechanism that is more effortful than elaborative rehearsal processes. In the present work, we test this hypothesis by implementing a double-item presentation within the item-method directed forgetting paradigm. Participants studied two unrelated items at a time. Some words were followed by the same cue, and participants were instructed to remember or forget both items (pure condition). On other trials, participants were to remember one but forget the other word (mixed condition). Selective rehearsal and inhibition accounts make distinct predictions regarding memory performance in the double-item presentation. In Experiment 1, we compared recognition performance in the pure and mixed conditions, while in Experiment 2, we included a neutral baseline condition to further distinguish between the selective rehearsal and inhibition accounts. Contrary to the inhibition account but consistent with selective rehearsal, we found for both remember and forget items that recognition was greater in the mixed than in the pure condition. Recognition for forget items also did not differ from neutral items. We conclude that selective rehearsal, not inhibition, is responsible for item-method directed forgetting.
\end{abstract}

Keywords Item-method directed forgetting $\cdot$ Selective rehearsal $\cdot$ Double presentation $\cdot$ Attentional inhibition

\section{Introduction}

The essential role of forgetting is often overshadowed by the negative consequences associated with the inability to remember something. However, forgetting outdated or traumatic information is crucial for cognitive efficiency (Bjork, Bjork, \& Anderson, 1998). One method developed to study intentional forgetting in the laboratory is the item-method paradigm. In this procedure, each item on the study list is followed by a cue to remember (R) or forget (F) (Geiselman, 1974; MacLeod,

Pelin Tan

pelin.tan@uwaterloo.ca

1 Department of Psychology, University of Waterloo, Waterloo, ON, Canada

2 Department of Psychology, California State University, Bakersfield, CA, USA

3 Department of Psychology, Wilfrid Laurier University, Waterloo, ON, Canada

4 Department of Psychology, Queen's University, Kingston, ON, Canada
1989; Quinlan \& Taylor, 2014; Thompson, Fawcett, \& Taylor, 2011; for reviews, see Basden \& Basden, 1998; Bjork, 1998; MacLeod, 1998). The standard finding is that memory is better for $\mathrm{R}$ compared to $\mathrm{F}$ items, a directed forgetting effect. Directed forgetting has been demonstrated across multiple memory paradigms using a variety of stimuli (Ahmad, Tan, \& Hockley, 2019; Ensor, Bancroft, \& Hockley, 2019; Hauswald \& Kissler, 2008; MacLeod, 1975; Quinlan, Taylor, \& Fawcett, 2010).

According to the selective rehearsal account of directed forgetting (Bjork, 1972; MacLeod, 1975), participants use maintenance rehearsal to keep items in working memory until presentation of the $\mathrm{R}$ or $\mathrm{F}$ cue. If an $\mathrm{R}$ cue is presented, participants engage in elaborative rehearsal to transfer the item to long-term memory; if an $\mathrm{F}$ cue is presented, participants cease rehearsal and allow the item to decay. Therefore, according to this account, remembering is cognitively demanding, but forgetting is passive.

In contrast to the passive view of forgetting inherent in the selective rehearsal account, recent research using a wide variety of paradigms suggests that forgetting is an active, cognitively demanding process (Anderson, 2003; Anderson \& Hanslmayr, 2014; Anderson \& Levy, 2009; Bjork, 1989; 
Bjork, 2007). According to the inhibition account of directed forgetting (see, e.g., Basden \& Basden, 1998; Basden, Basden, \& Gargano, 1993; Bjork, 1989; Geiselman \& Bagheri, 1985; Weiner \& Reed, 1969), an active, inhibitory mechanism is deployed to purge $\mathrm{F}$ items from memory.

The selective rehearsal and inhibition accounts, then, differ on whether forgetting is passive or effortful. In one study, Fawcett and Taylor (2008) had subjects respond to visualdetection probes during the study phase of an item-based directed-forgetting experiment. Interestingly, response times to the probes were slower following $\mathrm{F}$ cues than following $\mathrm{R}$ cues, suggesting that the cognitive demands of forgetting exceeded those of remembering (for similar findings, see Fawcett \& Taylor, 2010, 2012; Taylor, 2005).

In the present study, we used a novel variant of the itemmethod paradigm to investigate the cognitive demands of remembering and forgetting. Rather than presenting participants with one word at a time (as in the standard item-method paradigm), we presented unrelated word pairs. Word pairs were followed by two R cues (the "pure R" condition), two F cues (the "pure F" condition), or one $\mathrm{R}$ cue and one $\mathrm{F}$ cue (the "mixed" condition). Critically, the selective-rehearsal and inhibition accounts make divergent predictions for this paradigm.

Assume participants have a limited "number" of cognitive resources, $C$. When a cognitive task's demands exceed $C$, performance on the task, or a secondary task, suffers. Let $C_{R}$ denote the resources required to remember an item following an R cue, and let $C_{F}$ denote the resources required to forget an item following an $\mathrm{F}$ cue. Then, $2 C_{R}$ resources are required on a pure-R trial, $2 C_{F}$ resources are required on a pure-F trial, and $C_{R}+C_{F}$ resources are required on a mixed trial. The cognitive resources consumed by the mixed condition will necessarily be the mean of the cognitive resources consumed by the two pure trials (i.e., $\left.C_{R}+C_{F}=\left(2 C_{R}+2 C_{F}\right) / 2\right)$. The critical question, then, is whether $C_{R}>C_{F}$ or $C_{F}>C_{R}$; this is the question on which the selective rehearsal/inhibition debate hinges.

The selective rehearsal and inhibition accounts assign different values to $C_{R}$ and $C_{F}$, leading to different predictions. First, consider the selective rehearsal account, in which remembering is effortful and forgetting is passive. Here, $0 \leq$ $C_{F}<C_{R}$, with forgetting assumed to be passive and requiring few to no resources. Therefore, the resources required for a pure $\mathrm{R}$ trial exceed those required for a mixed trial, which exceed those required for a pure $\mathrm{F}$ trial (i.e., $2 C_{R}>C_{R}+C_{F}>$ $\left.2 C_{F}\right)$. Performance, then, should be better on mixed $\mathrm{R}$ items than pure $\mathrm{R}$ items, since the cognitive load is lighter on mixed trials than pure $\mathrm{R}$ trials. Since $C_{F}$ is close to 0 , performance on $\mathrm{F}$ items should be unaffected by the secondary task (i.e., forgetting another item or remembering another item).

In the inhibition account, forgetting is more effortful than remembering (Fawcett \& Taylor, 2008), so $0<C_{R}<C_{F}$. Here, pure $\mathrm{F}$ trials impose a heavier cognitive load than mixed trials, which impose a heavier load than pure $\mathrm{R}$ trials (i.e., $2 C_{F}>$ $C_{R}+C_{F}>2 C_{R}$ ). This is consistent with Fawcett and Taylor's finding that response times were longer during an $\mathrm{F}$ cue than an R cue. In the present study, the "secondary" task is either remembering another item or forgetting another item, and performance on both tasks (i.e., remembering/forgetting) should decline as the secondary task's cognitive demands increase. In other words, forgetting should be less successful when the secondary task is forgetting rather than remembering (because $C_{F}>C_{R}$ ), and remembering should be less successful when the secondary task is forgetting. Therefore, the inhibition account predicts better memory for pure $\mathrm{F}$ items than mixed $\mathrm{F}$ items and better memory for pure $\mathrm{R}$ items than mixed $\mathrm{R}$ items.

\section{Experiment 1}

\section{Method}

Participants Data from 52 undergraduate students were collected based on an a priori power analysis with a desired power of $.80(\alpha=.05)$ to detect a Cohen's $d$ of 0.3 . We conservatively estimated the directed forgetting effect in our mixed cue condition would be half the size of the standard item-method directed forgetting effect (Ahmad et al., 2019; Fawcett \& Taylor, 2008). Participants received course credit as compensation. All participants reported no previous participation in other directed-forgetting studies, normal to corrected-to-normal vision, and fluency in English. Three participants were excluded for not following experimental instructions. Two participants were excluded due to their failure to perform above-chance on the recognition test.

Materials Stimuli were 200 words from the MRC Psycholinguistic Database (Coltheart, 1981) with familiarity, concreteness, and imageability values between 400 and 600 . Kucera-Francis written frequencies ranged from 11 to 220 (Kucera \& Francis, 1967).

\section{Procedure}

Study phase Each trial began with a 1-s fixation in the center of the screen. Immediately following fixation offset, two words appeared for $4 \mathrm{~s}$, with one above and one below fixation. After word-pair offset, R/F cues appeared in the same location as the words for $3 \mathrm{~s}$. On pure R trials, both cues were Rs; on pure F trials, both cues were Fs; and on mixed trials, one cue was an R and the other was an F. On half the mixed trials, $\mathrm{R}$ appeared above and $\mathrm{F}$ appeared below fixation. On the other half, $\mathrm{F}$ appeared above and $\mathrm{R}$ appeared below (Fig. 1). The study phase began following a brief practice phase that familiarized participants with the procedure. The study phase consisted of 48 word-pair critical trials (evenly divided among 

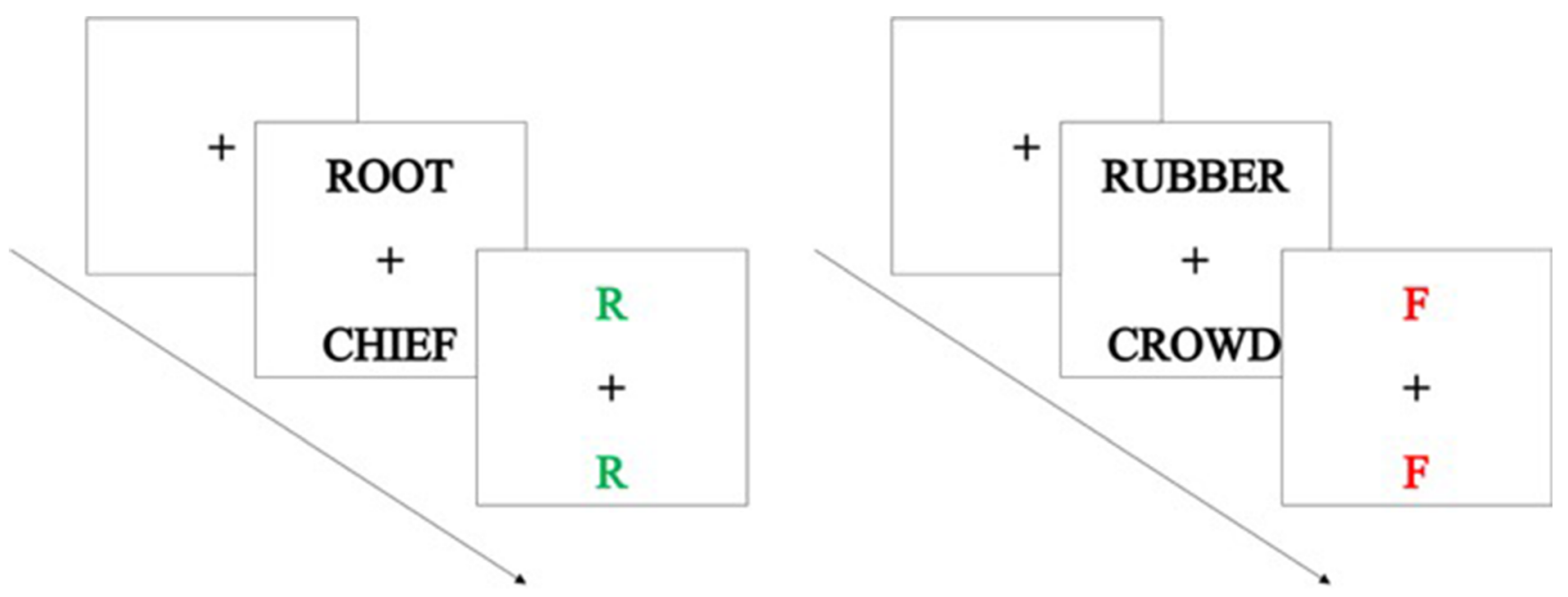

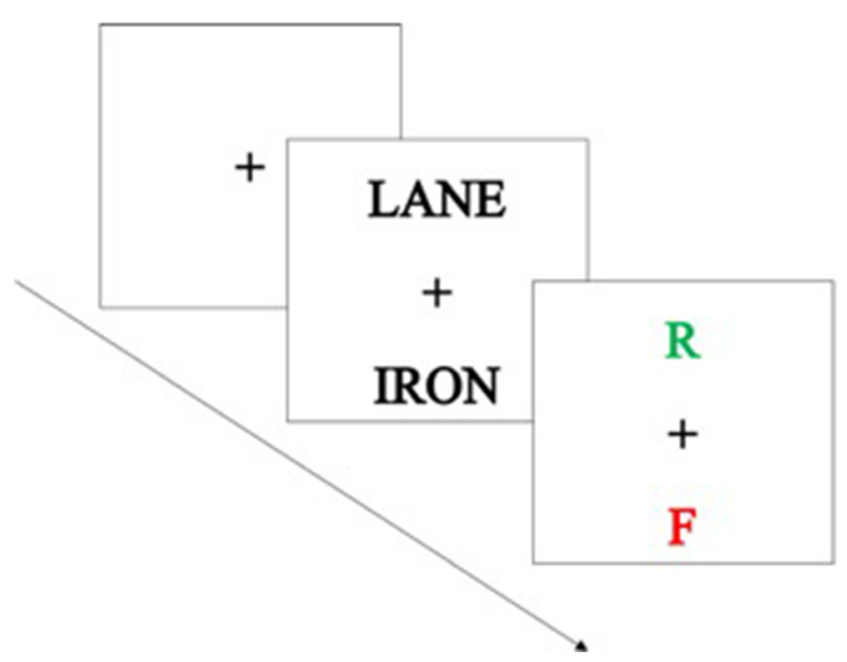

Fig. 1 Schematic representation of a single study-phase trial for the (a) pure R condition, (b) pure F condition, (c) mixed condition, where the $\mathrm{R}$ cue was presented above the fixation stimulus and the $\mathrm{F}$ cue was

the four trial types: RR, FF, RF, FR), two primary buffers, and two recency buffers. We programmed custom software on Matlab to randomly assign a total of 96 single study words to each of our conditions from the master word list of 200 words. We performed this randomization to generate unique stimulus combinations across conditions and participants. These randomizations were programmed according to the instructions provided by Taylor, Quinlan, and Vullings (2018).

Participants were told that only R items would be tested. They were informed that two words will appear on the screen at the same time but were never explicitly told to make associations.

Test phase Immediately following the study phase, the experimenter provided on-screen and verbal instructions for completing an old/new recognition test. Participants were instructed that, contrary to what they were told during the study phase, both R and $\mathrm{F}$ items would be tested. The test phase consisted of 192 items: the 96 study phase items and 96 distractors. Participants studied old items in pairs, but at test, each item from the study

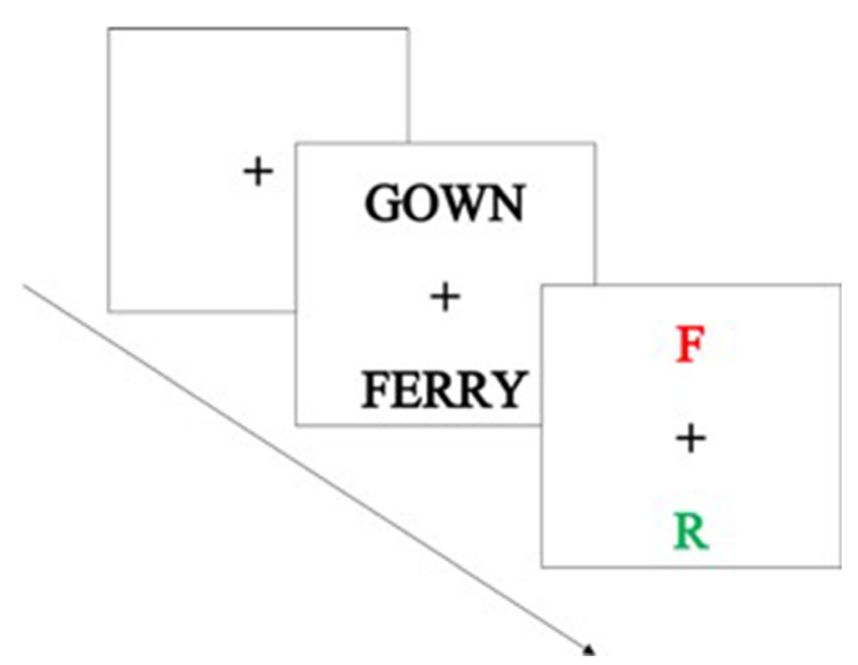

presented below, and (d) mixed condition, where the $\mathrm{F}$ cue was presented above the fixation stimulus and the $\mathrm{R}$ cue was presented below

were tested individually. For each probe, participants pressed the Z key if they thought it was "old" and the / key otherwise.

\section{Results and discussion}

Corrected recognition scores (hit rate minus false alarm rate) are shown in Table 1. The mean false-alarm rate (FAR) was

Table 1 Mean corrected recognition scores (hit rate minus false alarm rate) for the remember and forget items in pure and mixed conditions for Experiments 1 and 2

\begin{tabular}{lllll}
\hline Experiment & Cue condition & Remember & Forget & Neutral \\
\hline 1 & Mixed & $.47(.03)$ & $.27(.02)$ & - \\
& Pure & $.41(.03)$ & $.22(.02)$ & - \\
2 & Mixed & $.49(.03)$ & $.26(.02)$ & - \\
& Pure & $.43(.03)$ & $.21(.02)$ & - \\
& Neutral & - & - & $.23(.02)$ \\
\hline
\end{tabular}

Note. Standard error appears in parenthesis 
0.16. A 2 (cue: R vs. F) $\times 2$ (trial type: pure vs. mixed) repeated-measures analysis of variance (ANOVA) on corrected recognition scores produced a main effect of cue, $F(1,46)=17.41, p<.001, \eta_{\mathrm{p}}^{2}=.274$, demonstrating the expected directed-forgetting effect. The main effect of trial type was also significant, $F(1,46)=117.44, p<.001, \eta_{\mathrm{p}}^{2}=$ .719 , with better memory in the mixed condition than the pure condition. The interaction was not significant $(F<1)$.

Planned paired-samples $t$ tests compared performance on $\mathrm{R}$ and $\mathrm{F}$ items as a function of trial type. Mixed $\mathrm{R}$ performance $(M=.47, S E=.03)$ was higher than pure R performance $(M=$ $.41, S E=.03), t(46)=3.09, p=.003, d=0.45$. Mixed $\mathrm{F}$ performance $(M=.27, S E=.02)$ was also higher than pure F performance $(M=.22, S E=.02), t(46)=2.37, p=.022, d=$ 0.35 . A parallel set of mixed-effects logistic regression analyses demonstrated a qualitatively similar pattern of results.

Results from Experiment 1 were consistent with the selective rehearsal account. According to this account, remembering is effortful but forgetting is passive. As predicted, performance on mixed $\mathrm{R}$ items exceeded performance on pure $\mathrm{R}$ items, since rehearsing two items should use more resources than rehearsing one item while forgetting a second. This finding is inconsistent with inhibition, in which forgetting is more effortful than remembering. Because mixed trials should impose a greater cognitive load than pure $\mathrm{R}$ trials, the inhibition account predicts that pure $\mathrm{R}$ performance should be greater than mixed $\mathrm{R}$ performance.

F-item performance was inconsistent with inhibition, according to which forgetting should be more successful when accompanied by remembering than when accompanied by forgetting (i.e., memory for pure $\mathrm{F}$ items should exceed memory for mixed $\mathrm{F}$ items). We found the opposite pattern such that memory for mixed $\mathrm{F}$ items was greater than for pure $\mathrm{F}$ items.

The results of Experiment 1 are inconsistent with the inhibition account posited by Fawcett and Taylor (2008). An assumption of that account is that $C_{F}>C_{R}$ - that is, forgetting is more effortful than remembering. However, is this assumption necessary for inhibition? One can certainly conceive of an inhibition model in which $C_{R}=C_{F}$ or $C_{R}>C_{F}$. Such a framework would still assume the presence of an active inhibitory mechanism, in contrast to the selective rehearsal account, in which forgetting is passive. Experiment 2 was designed to provide a more general test of inhibition in item-method directed forgetting. In Experiment 2, we replicated the basic methods of Experiment 1 but added a neutral condition that served as a baseline memory measure. On neutral trials, following study of the word pair, participants advanced directly to the next trial, without the 3-s cue presentation (Fig. 2). Participants were instructed to not attend to the items (e.g., "do nothing") on neutral trials.

According to the selective rehearsal account, the neutral condition should act much like standard forget conditions: Participants are not afforded the 3-s cue for elaborative rehearsal, so the neutral items can benefit only from relatively

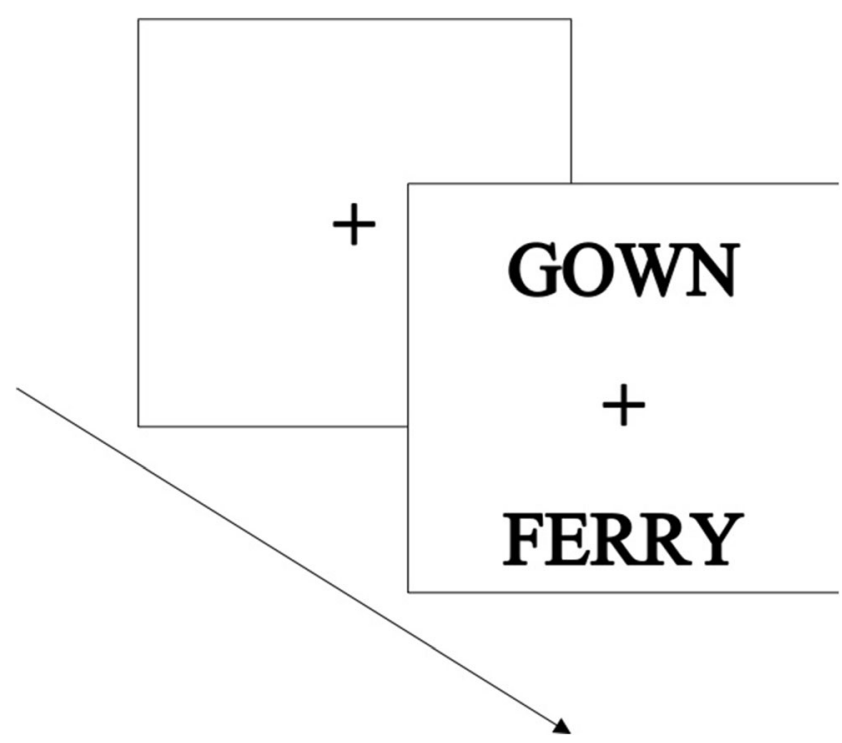

Fig. 2 Schematic representation of a single study-phase trial in the neutral condition, where the 3 -s cue presentation was removed and the next trial immediately began following word presentation

shallow maintenance rehearsal. According to the inhibition account, however, neutral items should be better remembered than $\mathrm{F}$ items. This is because, without the 3 -s cue, there is no time for the inhibitory mechanisms to be deployed. Without inhibition deployment, active forgetting cannot occur.

\section{Experiment 2}

\section{Method}

Participants Fifty-one undergraduates from Queen's University participated in exchange for course credit. Data from three participants were excluded due to their failure to perform above-chance on the recognition test and one participant was excluded for not following instructions.

Materials and procedure With the addition of the neutral condition, the study phase now included 60 trials (12 RR, $12 \mathrm{FF}$, $12 \mathrm{RF}, 12 \mathrm{FR}$, and 12 neutral trials). The procedure remained identical to Experiment 1, with the exception that participants were instructed to not attend to neutral trials (e.g., "do nothing"). The test phase included 240 words, with 120 study items and 120 distractors.

\section{Results and discussion}

Corrected recognition scores are shown in Table 1. The mean FAR was 0.17. A one-way repeated-measures ANOVA was performed on stimulus type (pure R, pure $\mathrm{F}$, mixed $\mathrm{R}$, mixed $\mathrm{F}$, and neutral). The omnibus test was significant, $F(4,184)=$ $52.61, p<.001, \eta_{\mathrm{p}}^{2}=.534$. Both pure $\mathrm{R}(M=.43, S E=.03)$ 
and mixed R performance $(M=.49, S E=.03)$ were higher than neutral performance $(M=.23, S E=.02), F(1,46)=$ 49.25, $p<.001, \eta_{\mathrm{p}}^{2}=.517$ and $F(1,46)=87.36, p<.001$, $\eta_{\mathrm{p}}^{2}=.655$, respectively. Neither pure $\mathrm{F}(M=.21, S E=.02)$ nor mixed $\mathrm{F}$ performance $(M=.26, S E=.02)$ differed from neutral performance $\left(F_{\mathrm{S}}<1.35\right)$.

To observe whether we replicated our findings from Experiment 1, we also conducted a 2 (cue: R vs. F) $\times 2$ (trial: pure vs. mixed) repeated-measures ANOVA. There was a main effect of cue, $F(1,46)=13.12, p<.001, \eta_{p}^{2}=.222$, demonstrating a directed-forgetting effect. The main effect of trial type was significant, $F(1,46)=108.18, p<.001, \eta_{\mathrm{p}}^{2}=$ .702 , with higher performance for mixed items than pure items. The interaction was not significant $(F<1)$. Pairedsamples $t$ tests showed that mixed R performance was significantly higher than pure R performance, $t(46)=2.87, p=.006$, $d=0.42$, and mixed $\mathrm{F}$ performance was higher than pure $\mathrm{F}$ performance, $t(46)=2.39, p=.021, d=0.35$. A parallel set of mixed-effects logistic regression analyses demonstrated a qualitatively similar pattern of results.

Experiment 2 replicated the results of Experiment 1 and were again consistent with the selective rehearsal account and inconsistent with inhibition. Critically, the finding that neither pure $\mathrm{F}$ nor mixed $\mathrm{F}$ performance differed from the neutral condition further ruled out the role of an active inhibitory mechanism. If this mechanism is deployed upon instructions to forget, then any reasonably effective inhibitory mechanism should drive $\mathrm{F}$ performance below neutral. That is, compared to a neutral condition in which individuals are instructed to ignore an item, providing individuals $3 \mathrm{~s}$ to forget an item proved ineffective, suggesting that individuals were not able to implement an inhibitory mechanism. Furthermore, the finding of better memory for pure $\mathrm{R}$ and mixed $\mathrm{R}$ items compared to the neutral items also converged on the conclusion that selective rehearsal provides the best account of our findings.

\section{General discussion}

In the present study, we used a novel variant of the itemmethod paradigm to investigate the viability of the selective rehearsal and inhibition accounts. During the study phase, participants saw word pairs rather than single items, and these word pairs were followed by pure cues (RR or FF) or mixed cues (RF or FR). At test, memory for single words was tested using old/new recognition. In Experiment 1, we demonstrated that memory for mixed $\mathrm{R}$ items was better than for pure $\mathrm{R}$ items, and that memory for mixed $\mathrm{F}$ items was better than for pure $\mathrm{F}$ items. Both of these findings are at odds with the view that forgetting is more effortful than remembering (Fawcett \& Taylor, 2008). Such a finding, however, is consistent with the passive view of forgetting posited by the selective rehearsal account. Experiment 2 replicated the results of Experiment 1 and additionally showed that both pure $\mathrm{F}$ and mixed $\mathrm{F}$ item performance did not differ from neutral item memory. This further supported the view that there was no inhibitory process being implemented to facilitate forgetting.

Across several studies, Fawcett and Taylor (2008, 2010, 2012) demonstrated that performance on a secondary task is better following an $\mathrm{R}$ cue than an $\mathrm{F}$ cue. For example, response times to visual-detection probes were longer during $\mathrm{F}$ trials than R trials. Our results are inconsistent with this view: If forgetting is more effortful than remembering, then remembering two $\mathrm{R}$ items $\left(2 C_{R}\right)$ should consume fewer cognitive resources than remembering one item while actively forgetting the other $\left(C_{R}+C_{F}\right)$. We also observed the opposite pattern predicted by an inhibition account for $\mathrm{F}$ performance. The inhibition account predicts better memory for pure $F$ than mixed $F$ items because pure $F$ trials impose a heavier cognitive load than mixed trials. Finally, the finding in Experiment 2 that $\mathrm{F}$ item performance did not differ from neutral item performance rules out more general inhibition accounts.

How can our results be reconciled with Fawcett and Taylor's (2008, 2010, 2012) behavioral data? One possibility is that their results reflect a task-switching effect rather than an inhibition effect. During item presentations, subjects are thought to engage in maintenance rehearsal until presentation of the R or F cue. When an R cue is presented, subjects continue encoding processes; conversely, when an $\mathrm{F}$ item is presented, subjects end rehearsal and, presumably, switch their attention to previously encoded items. This task switch may be sufficiently demanding to increase response times to a secondary task during cue presentation.

Our results support the selective rehearsal account. In both experiments, mixed $\mathrm{R}$ words were better recognized than pure $\mathrm{R}$ words, consistent with the view that remembering is more effortful than forgetting. Recall that, if remembering is more effortful, then remembering two $\mathrm{R}$ items $\left(2 C_{R}\right)$ will consume more cognitive resources than remembering one item and forgetting another $\left(C_{R}+C_{F}\right)$, thereby diminishing performance. Notice, as well, that equivalent performance for $\mathrm{F}$ and neutral items is also consistent with selective rehearsal: In the selective rehearsal account, forgetting is passive, and recognition of $\mathrm{F}$ items stems entirely from the initial maintenance rehearsal used to maintain the item in working memory until the instruction cue is presented. If an F cue is presented, rehearsal stops. Under this framework, then, $\mathrm{F}$ and neutral items would receive the same degree of encoding, and thus should be recognized at the same rate.

Our findings on the differential resource depletion by $\mathrm{R}$ and F items are supported by Popov, Marevic, Rummel, \& Reder, (2019). They applied a formal mathematical model of resource depletion (Popov \& Reder, 2019) to examine a novel directed-forgetting after-effect. Their findings revealed that memory for a studied item (regardless of whether it was $\mathrm{R}$ 
or $\mathrm{F}$ item) was worse if the preceding study item was $\mathrm{R}$ rather than $\mathrm{F}$ and that the effect is cumulative; the more $\mathrm{R}$ items were in a row; the worse memory was for the subsequent item. In both experiments, Popov et al. demonstrated the directed forgetting after-effects were not attenuated even when participants were instructed to perform concurrent suppression and divided attention tasks within an item-method directed forgetting paradigm. Their results purport a similar conclusion to our findings where $\mathrm{R}$ items deplete more resources than $\mathrm{F}$ items, leaving fewer resources to process additional items.

While our finding of better memory for mixed $\mathrm{F}$ items than pure $\mathrm{F}$ items is inconsistent with the inhibition account, we also acknowledge that it is not directly consistent with the selective rehearsal account. One potential explanation is that, during the maintenance rehearsal phase (i.e., after pair onset but before cue presentation), subjects associate the two words with each other. Then, when they are given an RF or FR instruction, the elaborative rehearsal of the $\mathrm{R}$ item involves some inadvertent rehearsal of the F item, owing to their association. Still another potential explanation involves context. Since the $\mathrm{R}$ and $\mathrm{F}$ items are presented simultaneously, they are presented within the same context. Then, even if subjects cease rehearsal of the F item, its association with the context it shares with the R item slightly boosts its memorability. ${ }^{1}$ Note that, to explain the advantage for mixed $F$ over pure $F$ items, these explanations need only apply to a small subset of mixed trials. Clearly, although mixed $\mathrm{F}$ items were better recognized than pure F items, they were still recognized at a much lower rate than $\mathrm{R}$ items.

Our findings revealed selective rehearsal as the core process underlying item-method directed forgetting, and cast doubt on the inhibition account. We should note that, although we are skeptical of the role of inhibition in item-method directed forgetting, we do not, here, take a position on inhibition in other memory paradigms (Anderson, 2003). For example, list-method directed forgetting has often been attributed to inhibition (Basden \& Basden, 1998; Basden et al., 1993; also cf. MacLeod, Dodd, Sheard, Wilson, \& Bibi, 2003; Sahakyan \& Kelley, 2002); our results neither shed light on nor do we take a position on the viability of this account. Instead, our results confirm that selective rehearsal, not inhibition, drives item-method directed forgetting.

\section{References}

Ahmad, F. M., Tan, P., \& Hockley, W. E. (2019). Directed forgetting for categorised pictures: Recognition memory for perceptual details versus gist. Memory, 27, 894-903. https://doi.org/10.1080/09658211. 2019.1591456

\footnotetext{
${ }^{1}$ We would like to thank Vencislav Popov for providing this alternative explanation and for feedback.
}

Anderson, M. C. (2003). Rethinking interference theory: Executive control and the mechanisms of forgetting. Journal of Memory and Language, 49, 415-445. https://doi.org/10.1016/j.jml.2003.08.006

Anderson, M. C., \& Hanslmayr, S. (2014). Neural mechanisms of motivated forgetting. Trends in Cognitive Sciences, 18, 279-292. https:// doi.org/10.1016/j.tics.2014.03.002

Anderson, M. C., \& Levy, B. J. (2009). Suppressing unwanted memories. Current Directions in Psychological Science, 18, 189-194. https:// doi.org/10.1111/j.1467-8721.2009.01634.x

Basden, B. H., \& Basden, D. R. (1998). Directed forgetting: A contrast of methods and interpretations. In J. M. Golding \& C. M. MacLeod (Eds.), Intentional forgetting: Interdisciplinary approaches (pp. 139172). Mahwah, NJ: Lawrence Erlbaum Associates Publishers.

Basden, B. H., Basden, D. R., \& Gargano, G. J. (1993). Directed forgetting in implicit and explicit memory tests: A comparison of methods. Journal of Experimental Psychology: Learning, Memory, and Cognition, 19, 603-613. https://doi.org/10.1037/0278-7393.19.3. 603

Bjork, E. L., Bjork, R. A., \& Anderson, M. C. (1998). Varieties of goaldirected forgetting. In J. M. Golding \& C. M. MacLeod (Eds.), Intentional forgetting: Interdisciplinary approaches (pp. 103-137). Mahwah, NJ: Lawrence Erlbaum Associates Publishers.

Bjork, R. A. (1972). Theoretical implications of directed forgetting. In A. W. Melton \& E. Martin (Eds.), Coding processes in human memory (pp. 217-235). Washington, DC: Winston.

Bjork, R. A. (1989). Retrieval inhibition as an adaptive mechanism in human memory. In H. L. Roediger \& F. I. M. Craik (Eds.), Varieties of memory and consciousness: Essays in honour of Endul Tulving (pp. 309-330). Hillsdale, NJ: Erlbaum.

Bjork, R. A. (1998). Intentional forgetting in perspective: Comments, conjectures, and some directed remembering. In J. M. Golding \& C. M. MacLeod (Eds.), Intentional forgetting: Interdisciplinary approaches (pp. 453-481). Hillsdale, NJ: Lawrence Erlbaum Associates.

Bjork, R. A. (2007). Inhibition: An essential and contentious concept. In H. L. Roediger, Y. Dudai, \& S. M. Fitzpatrick (Eds.), Science of memory: Concepts (pp. 307-313). Oxford, England: Oxford University Press.

Coltheart, M. (1981). The MRC Psycholinguistic Database. The Quarterly Journal of Experimental Psychology A: Human Experimental Psychology, 33A(4), 497-505. https://doi.org/10. 1080/14640748108400805

Ensor, T. M., Bancroft, T. D., \& Hockley, W. E. (2019). Listening to the picture-superiority effect: Evidence for the conceptualdistinctiveness account of picture superiority in recognition. Experimental Psychology, 66, 134-153. https://doi.org/10.1027/ 1618-3169/a000437

Fawcett, J. M., \& Taylor, T. L. (2008). Forgetting is effortful: Evidence from reaction time probes in an item-method directed forgetting task. Memory \& Cognition, 36, 1168-1181. https://doi.org/10. 3758/MC.36.6.1168

Fawcett, J. M., \& Taylor, T. L. (2010). Directed forgetting shares mechanisms with attentional withdrawal but not with stop-signal inhibition. Memory \& Cognition, 38, 797-808. https://doi.org/10.3758/ MC.38.6.797

Fawcett, J. M., \& Taylor, T. L. (2012). The control of working memory resources in intentional forgetting: Evidence from incidental probe word recognition. Acta Psychologica, 139, 84-90. https://doi.org/ 10.1016/j.actpsy.2011.10.001

Geiselman, R. E. (1974). Positive forgetting of sentence material. Memory \& Cognition, 2, 677-682. https://doi.org/10.3758/ BF03198138

Geiselman, R. E., \& Bagheri, B. (1985). Repetition effects in directed forgetting: Evidence for retrieval inhibition. Memory \& Cognition, 13, 57-62.https://doi.org/10.3758/BF03198444 
Hauswald, A., \& Kissler, J. (2008). Directed forgetting of complex pictures in an item method paradigm. Memory, 16, 797-809. https:// doi.org/10.1080/09658210802169087

Kucera, H., \& Francis, W. N. (1967). Computational analysis of presentday American English. Providence, RI: Brown University Press.

MacLeod, C. M. (1975). Long-term recognition and recall following directed forgetting. Journal of Experimental Psychology: Human Learning and Memory, 1, 271-279. https://doi.org/10.1037/02787393.1.3.271

MacLeod, C. M. (1989). Directed forgetting affects both direct and indirect tests of memory. Journal of Experimental Psychology: Learning, Memory, and Cognition, 15, 13-21. https://doi.org/10. 1037/0278-7393.15.1.13

MacLeod, C. M. (1998). Directed forgetting. In J. M. Golding \& C. M. MacLeod (Eds.), Intentional forgetting: Interdisciplinary approaches (pp. 1-57). Mahwah, NJ: Lawrence Erlbaum Associates Publishers.

MacLeod, C. M., Dodd, M. D., Sheard, E. D., Wilson, D. E., \& Bibi, U. (2003). In opposition to inhibition. In B. H. Ross (Ed.), Psychology of learning and motivation: Advances in research and theory (vol. 43, pp. 163-214). New York, NY: Elsevier Science.

Popov, V., Marevic, I., Rummel, J., \& Reder, L. (2019). Forgetting is a Feature, not a Bug: Intentionally Forgetting Some Things Helps Us Remember Others by Freeing up Working Memory Resources. Psychological Science 30(9), 1303-1317. https://doi.org/10.1177/ 0956797619859531

Popov, V. \& Reder, L. (2019). Frequency Effects on Memory: A Resource-Limited Theory. Psychological Review. Advanced Online Publication

Quinlan, C. K., \& Taylor, T. L. (2014). "I never forget a face, but in your case I'll be glad to make an exception": Intentional forgetting of emotional faces. Canadian Journal of Experimental Psychology, 68, 212-221. https://doi.org/10.1037/cep0000024

Quinlan, C. K., Taylor, T. L., \& Fawcett, J. M. (2010). Directed forgetting: Comparing pictures and words. Canadian Journal of Experimental Psychology, 64, 41-46. https://doi.org/10.1037/ a0016569
Sahakyan, L., \& Kelley, C. M. (2002). A contextual change account of the directed forgetting effect. Journal of Experimental Psychology: Learning, Memory, and Cognition, 28, 1064-1072. https://doi.org/ 10.1037/0278-7393.28.6.1064

Taylor, T.L. (2005) Inhibition of return following instructions to remember and forget. The Quarterly Journal of Experimental Psychology, 58A(4), 613-629. https://doi.org/10.1080/02724980443000115

Taylor, T.L., Quinlan, C.K., and Vullings, K.C.H. (2018). Decomposing item-method directed forgetting of emotional pictures: equivalent costs and no benefits. Memory \& Cognition, 46(1), 132-147. https://doi.org/10.3758/s13421-017-0751-y

Thompson, K. M., Fawcett, J. M., \& Taylor, T. L. (2011). Tag, you're it: Tagging as an alternative to yes/no recognition in item method directed forgetting. Acta Psychologica, 138, 171-175. https://doi.org/ 10.1016/j.actpsy.2011.06.001

Weiner, B., \& Reed, H. (1969). Effects of the instructional sets to remember and to forget on short-term retention: Studies of rehearsal control and retrieval inhibition (suppression). Journal of Experimental Psychology, 79, 226-232. https://doi.org/10.1037/h0026951

Publisher's note Springer Nature remains neutral with regard to jurisdictional claims in published maps and institutional affiliations.

This study was conducted by P.T. for her MSc thesis under the supervision of D.E.W. We thank Michelle Blumberg and Emma Caplan for collecting the data. We also would like to thank Colin M. MacLeod for feedback and encouragement. 